\title{
Editorial
}

\section{The importance of identification for a stress urinary incontinence after pelvic organ prolapse vaginal repair}

Hariyono Winarto

Check for updates

Pelvic organs prolapse (POP) and stress urinary incontinence (SUI) are the two specific health-related diseases in women globally. They may coexist in most affected patients because the predisposing factors are similar. ${ }^{1}$ Both diseases may emerge due to several conditions, such as anatomical impairment in the female pelvic floor support (i.e., fascial defects), muscular defect, denervation damage, or as a consequence of post POP vaginal repair. ${ }^{2,3}$ Women with POP may be continent despite losing vaginal and urethral support due to either kinking or external constriction of the urethra. Indeed, some women without a complaint of SUI presurgical may develop SUI following POP vaginal repair called postoperative stress urinary incontinence or de novo SUI. It is distinct from the continent patients with POP which may also have incontinence preoperatively called 'occult' or 'masked' SUI, and it will arise when the prolapse is corrected. ${ }^{1}$ The effect of POP surgery on the presence of SUI is complex. POP surgery can result in the cure of SUI, which preoperatively had been hidden by POP. ${ }^{4}$

De novo $\mathrm{SUl}$ is an unexpected complication after POP surgery. It is challenging for every gynecologist. This problem may frustrate the caregivers and patients. The surgery that was first expected as the final solution bears another problem. Technically, this problem increases along with the frequent use of mesh, and it did not frequently happen when gynecologists only use the conventional technique or anterior colporrhaphy using vaginal tissue. ${ }^{5}$ Is the conventional procedure of surgery better concerning SUI complications? More studies are needed to answer this question. However, Wu et $\mathrm{al}^{6}$ mentioned that vaginal tissue is better in repairing surgery for POP regarding SUI complications. Studying the incidence and characteristics of de novo SUI is crucial to get the fundamental insight before exploring the real cause of SUI, particularly from the Asian countryside as the largest population by region worldwide.
Asian population also had a high POP incidence of approximately $19.7 \%$ (range $3.4-56.4 \%$ ) and urinary incontinence of about $28.7 \%$ (range $5.2-70.8 \%$ ). ${ }^{7}$ We believe that this research topic could result in unique attributes for a specific population.

A single-center cross-sectional study by Djusad et $\mathrm{al}^{8}$ published in this issue stated that de novo SUI after surgery within 18 months in treating POP was $8 \%$ in Indonesia, comparable with the current literature. The data were collected from the hospital registry in Indonesia's leading tertiary hospital, including 75 eligible patients between 2016 and 2017. The patient characteristics were: non-geriatrics women (mean $=56$ years), multiparity with more than three children, high body mass indexes (mean $=29 \mathrm{~kg} / \mathrm{m}^{2}$ ), menopause onset 12.8 years, and had de novo SUI within 6-7 months post-surgical procedures. The demographic data were undoubtedly considered the baseline data for the following research on this topic to delineate further the exact risk factor or even predictor of de novo SUI.

However, the current research in Indonesia on this topic still yielded a small sample size that may limit comprehensive understanding of this disease entity. ${ }^{3,9,10}$ Therefore, it is highly recommended to conduct future large-scale prospective research studies with multiple years and multicenter involved to evaluate the de novo SUl's development further. Another question that should be answered is the incidence of de novo SUI following vaginal repair of POP with or without mesh.

\footnotetext{
Acknowledgment

Muhammad Habibburrachman MD supported technical and language editing.

From Medical Journal of Indonesia; Department of Obstetrics and Gynecology, Faculty of Medicine, Universitas Indonesia, Cipto Mangunkusumo Hospital, Jakarta, Indonesia pISSN: 0853-1773 • elSSN: 2252-8083

https://doi.org/10.13181/mji.ed.215971

Med J Indones. 2021;30:237-8
} 
Corresponding author:

Hariyono Winarto

E-mail: hariyonow@gmail.com

\section{REFERENCES}

1. Hafidh BA, Chou Q, Khalil MM, Al-Mandeel H. De novo stress urinary incontinence after vaginal repair for pelvic organ prolapse: one-year follow-up. Eur J Obstet Gynecol Reprod Biol. 2013;168(2):227-30.

2. Wang SY, Cao TT, Wang RZ, Yang X, Sun XL, Wang JL. Incidence and risk factors of de novo stress urinary incontinence after pelvic floor reconstruction: a nested case-control study. Chin Med J (Engl). 2017;130(6):678-83.

3. Al-Mandeel H, Ross S, Robert M, Milne J. Incidence of stress urinary incontinence following vaginal repair of pelvic organ prolapse in objectively continent women. Neurourol Urodyn. 2011;30(3):390-4.

4. Lensen EJ, Withagen MI, Kluivers KB, Milani AL, Vierhout ME. Urinary incontinence after surgery for pelvic organ prolapse. Neurourol Urodyn. 2012;32(5):455-9.
5. Kim A, Kim S, Kim HG. Current overview of surgical options for female stress urinary incontinence. Int Neurourol J. 2020;24(3):222-30.

6. Wu YM, Welk B. Revisiting current treatment options for stress urinary incontinence and pelvic organ prolapse: a contemporary literature review. Res reports Urol. 2019;11:179-88.

7. Walker GJ, Gunasekera P. Pelvic organ prolapse and incontinence in developing countries: review of prevalence and risk factors. Int Urogynecol J. 2011;22(2):127-35.

8. Djusad S, Nizomy IR, Hakim S, Priyatini T, Moegni F, Meutia AP, et al. Incidence and characteristics of de novo stress urinary incontinence after pelvic organ prolapse vaginal repair. Med J Indones. 2021;30(4):245-9.

9. Alas AN, Chinthakanan O, Espaillat L, Plowright L, Davila GW, Aguilar VC. De novo stress urinary incontinence after pelvic organ prolapse surgery in women without occult incontinence. Int Urogynecol J. 2017;28(4):583-90.

10. Kasturi S, Diaz SI, McDermott CD, Woodman PJ, Bump RC, Terry $\mathrm{CL}$, et al. De novo stress urinary incontinence after negative prolapse reduction stress testing for total vaginal mesh procedures: Incidence and risk factors. Am J Obstet Gynecol. 2011;205(5):487.e1-4. 